\title{
A Retrospective Study on Changes in Food Preferences of Japanese High School Students from Childhood to the Present Day
}

\author{
Tomoko Osera ${ }^{1,2}$, Mitsuyo Awai ${ }^{3}$, Setsuko Tsutie ${ }^{4}$, Misako Kobayashi ${ }^{2} \&$ Nobutaka Kurihara $^{1}$ \\ ${ }^{1}$ Hygiene and Preventive Medicine, Graduate School of Life Science, Kobe Women's University, Japan \\ ${ }^{2}$ Takakuradai Kindergarten attached to Kobe Women's University, Japan \\ ${ }^{3}$ School of Nursing, Kansai University of Nursing and Health Sciences 1456-4 Shichi, Awaji-city, 656-2131, \\ Japan \\ ${ }^{4}$ Clinical Nutrition Management, Graduate School of Life Science, Kobe Women’s University, Japan
}

Correspondence: Nobutaka Kurihara, MD, Graduate School of Life Science, Kobe Women's University, 2-1 Higashisuma-Aoyama, Suma, Kobe, Japan. Tel: 81-78-737-2417. E-mail: kurihara@ suma.kobe-wu.ac.jp

Received: May 13, 2017

doi:10.5539/jfr.v6n4p150
Accepted: June 17, 2017 Online Published: July 28, 2017

URL: https://doi.org/10.5539/jfr.v6n4p150

\begin{abstract}
Background: To conduct a retrospective study for investigating changes in food preferences of high school students from childhood to the present day. Methods: The study included 1,300 students aged 16-18 years who responded to a questionnaire regarding food items that they disliked at present and in their childhood; they selected a list of 55 foods and responded to 35 questions regarding their food habits. The distribution was categorized into four patterns of food preferences based on whether a particular student had disliked a particular food item during childhood (+) and during high school at present $(+)$. Food preference at present was examined for all other items using logistic regression analysis after adjusting for gender and age. Results: In total, 66.9\% of the subjects reported $(+)$ to $(+), 12.5 \%$ reported $(+)$ to $(-), 6.5 \%$ reported $(-)$ to $(+)$, and $14.1 \%$ reported $(-)$ to $(-)$. Even in the $(+)$ to $(+)$ group, a significant decrease was observed in the number of disliked foods from childhood $(5.5 \pm 5.4)$ to the present day $(4.2 \pm 4.1)(\mathrm{P}<0.001$, ANOVA). No dislike for any food item at present was related to no dislike for any food item during childhood [odds ratio (OR), 12.57 ; $95 \%$ confidence interval (CI), 8.3-19.1]] and talking positively about food (OR, 1.28; 95\% CI, 1.11-1.49) but inversely related to the limited use of smartphone while eating (OR, 0.86; 95\% CI, 0.75-0.98). Conclusion: Decreasing the dislike for foods at present as well as no dislike for any food item during childhood may be crucial for developing future good food habits in high school students. In addition, to improve current food preferences, students may need to eat together.
\end{abstract}

Keywords: food preferences, disliked food, high school students, childhood

\section{Introduction}

Early childhood is the most important period for establishing healthy eating habits and controlling the food preferences of children. Childhood is a crucial period for developing food acceptance patterns (Nicklas et al., 2001, Ilingworht \& Lister, 1964, Cashidan, 1994). Some investigators have insisted that preferences are shaped by a combination of genetic and environmental factors (Wardle \& Cooke, 2008). The development and long-term health of children is linked to food habits established from early childhood (Scaglioni et al, 2008). The correct food habits may continue in the future of children's life. In addition, children are exposed to unhealthy food choices, which may have greatly contributed to the increase in the prevalence of overweight observed among their youth in the past several years (St-Onge MP, 2003). Therefore, it is important to take correct food habits during childhood.

On the other hand, adolescence is a crucial period for the development of health status (Mechanic \& Hansell, 1987, Vingilis, Waed, \& Seeley, 2002, Vingilis, Wade, \& Seeley, 2007). During this period, health-related behaviors including smoking, alcohol consumption, drug use, nutrition-related behavior, and physical activities, are established (Sharma et al, 2016). Further, in this period, health is strongly affected by social factors, including income inequality, family support, school environment, and peer influence (Viner et al., 2012). The 
food group consumption varies by socioeconomic, demographic, and life style factors in young adults (Deshmukh-Taskar P, 2007).

However, it is unclear how food preferences during childhood influence those during high school. In this retrospective study, we investigated changes in the food preferences of high school students from childhood to the present day.

\section{Method}

\subsection{Participant (Subject) Characteristics}

This was a cross-sectional study. From May to November 2015, 1,300 students aged 16-18 years from 11 high schools in Japan were included in the study. Of all students enrolled in the study, 1,296 (99.7\%) completed and returned the questionnaire, and all provided informed consent for its use.

\subsection{Questionnaire}

The students answered a questionnaire regarding foods they disliked at present and in their childhood. They selected a list of 55 foods and answered 35 questions regarding their food habits.

This questionnaire is a revised version of the one originally created by the Japan Sports Council that was used to determine the food habits of high school students (Japan Sports Council, 2010, Osera et al., 2016a). Further questionnaire items addressed 'respect for food', utilising a 5-point rating scale. In addition, Self-rated heath (SRH) measures generally included questions, such as "How would you rate your overall health?," and offered five response categories that ranged from excellent to poor: Excellent, Very good, Good, Fair, and Poor (Joffer et al., 2016, Warnoff, et al., 2016, Wu et al, 2013).

The foods student disliked, which were chosen by themselves from a list of 55foods; Noodle, Rice, Bread, Konjaku, Sweet potato, Potate, Azuki beans, Soybeans, Freeze-dried tofu, Tofu, Deep-fried tofu, Sesame, Pampkin, Peas, String beans, Carrot, Leak, Green pepper, Broccoli, Spinach, Japanese mustard spinach, Cabbage, Cucumber, Burdock, Japanese radish, Onion, Corn, Eggplant, Chinese cabbage, Tomato, Cherry tomato, Banana, Tangerine, Apple, Pineapple, Enoki mashroom, Shimeji mashroom, Dried shitake, Toasted laver, Hijiki, Seaweed, Squid, Shrimp, Fish paste cake, Spanish mackerel, Sermon, Liver, Beef, Chicken, Pork, Cheese, Yogurt, Milk, Egg, Quail egg. The foods on the list were selected from what were available at regular school lunches and often disliked by children as shown in our previous study (Osera et al, 2016a).

The distribution was categorized into four patterns of food preferences based on whether a particular student had disliked a particular food item during childhood $(+)$ or not $(-)$, and during high school days at present $(+)$ or not $(-)$. For example, $(+)$ to $(-)$ means that the student disliked some foods during childhood while as high school students they had no dislikes, $(+)$ to $(+)$ means that the students disliked some foods as childhood and that they disliked some foods as high school days, $(-)$ to $(+)$ means that the students disliked no foods as childhood and that as high school days they disliked some foods, (-) to (-) means that the students disliked no foods as childhood and that they disliked no foods as high school days.

\subsection{Statistics and Data Analysis}

The analysis of variance (ANOVA) was used to compare each number of disliked foods between the time of childhood and at present groups in they have food preference. The chi-square test or Fisher's exact test was used to evaluate associations between independent variables and food preferences at the time of childhood and at high school age. McNemar test was used to assess the food preferences change from childhood to high school age. The percentage of high school students who disliked each food was significantly different from that of them in childhood. A probability $(\mathrm{P})$ value $<0.05$ was considered statistically significant (Figure 2 ).

All significant variables in the bivariate analysis were then entered into a logistic regression analysis. Food preference at present, the differences between those that disliked foods at present and they those that did not dislike any food at present, were examined for all the other items using logistic regression analysis after adjusting for gender and age. A dichotomy regression analysis was performed by setting a stepwise method. The sample data were entered and analyzed using SPSS for Windows, Version.23 (IBM, New York, NY).

\subsection{Ethics}

Students were informed as to the objects and methods of this study and answered the questionnaire only if they so desired, in the absence of any compelling force and with the right of free withdrawal. Individual privacy was strictly protected thorough the investigation. This study was approved by the leader of the high school. Under these conditions, students agreed with their corporation for the scientific investigations in the high schools, including this study, when their students entered. This study was approved by the Kobe Women's University 
Ethics Committee Regarding Human Subjects.

\section{Results}

\subsection{Relationship between Food Preferences and Physical Characteristics, Self-Rated Health}

Fisher's exact probability test and ANOVA revealed that the relationship between food preferences in childhood and at high school age and physical characteristics, self-rated health was statistically significant (Table 1). In males, a relationship between height, weight, and food preferences in childhood was observed $(\mathrm{P}<0.001)$; however, such a relationship was not observed at high school age $(\mathrm{P}=\mathrm{N}$.S $)$. Notably, no significant difference was observed in BMI in either gender during childhood and at high school age (Table 1).

\subsection{Relationships between Food Preferences during Childhood to High School Age}

Fisher's exact probability test revealed that the relationship between food preferences in childhood and current food preferences by gender was statistically significant (Table 2). In total, about $30 \%$ of the students answered "I do not know" or "I do not remember." In total, $66.9 \%$ of subjects reported (+) to $(+), 12.5 \%$ reported $(+)$ to $(-)$, $6.5 \%$ reported $(-)$ to $(+)$, and $14.1 \%$ reported $(-)$ to $(-)$ (Table 3$)$. Significant differences by age were observed.

Table 1. Comparison in characteristics of high school students between presence and absence of preferences

\begin{tabular}{|c|c|c|c|c|c|c|c|c|c|c|c|}
\hline & \multirow[t]{2}{*}{ Variable } & \multicolumn{4}{|c|}{ During childhood } & \multicolumn{5}{|c|}{ The present day } & \multirow{3}{*}{$\frac{\text { P value }}{0.000^{+++}}$} \\
\hline & & \multicolumn{2}{|c|}{ Presence $(+)$} & \multicolumn{2}{|c|}{ Absence $(-)$} & \multirow{2}{*}{$\frac{P \text { value }}{0.000^{+++}}$} & \multicolumn{2}{|c|}{ Presence $(+)$} & \multicolumn{2}{|c|}{ Absence (-) } & \\
\hline \multirow{3}{*}{ All } & Height (m) & 665 & $162.1 \pm 8.2$ & 167 & $165.0 \pm 8.9$ & & 857 & $161.5 \pm 8.2$ & 308 & $165.1 \pm 8.5$ & \\
\hline & Weight $(\mathrm{kg})$ & 615 & $54.3 \pm 9.2$ & 158 & $57.3 \pm 11.1$ & $0.000^{+++}$ & 791 & $54.1 \pm 9.4$ & 297 & $56.4 \pm 10.2$ & $0.000^{+++}$ \\
\hline & $\operatorname{BMI}\left(\mathrm{m} / \mathrm{kg}^{2}\right)$ & 616 & $20.5 \pm 2.7$ & 157 & $20.9 \pm 2.8$ & N.S & 791 & $20.6 \pm 2.7$ & 296 & $20.6 \pm 2.9$ & N.S \\
\hline \multirow{3}{*}{ Male } & Height (m) & 280 & $169.2 \pm 6.3$ & 88 & $171.3 \pm 6.7$ & $0.006^{++}$ & 311 & $169.4 \pm 6.1$ & 174 & $170.4 \pm 6.4$ & N.S \\
\hline & Weight (kg) & 277 & $59.7 \pm 9.3$ & 88 & $63.0 \pm 11.0$ & $0.006^{++}$ & 310 & $60.3 \pm 9.9$ & 173 & $60.5 \pm 9.9$ & N.S \\
\hline & $\operatorname{BMI}\left(\mathrm{m} / \mathrm{kg}^{2}\right)$ & 277 & $20.8 \pm 2.8$ & 87 & $21.5 \pm 3.2$ & N.S & 309 & $21.0 \pm 3.0$ & 172 & $21.0 \pm 3.0$ & N.S \\
\hline \multirow{3}{*}{ Female } & Height (m) & 385 & $156.9 \pm 5.0$ & 79 & $158.1 \pm 5.0$ & N.S & 546 & $156.9 \pm 5.3$ & 134 & $158.1 \pm 5.1$ & $0.027^{+}$ \\
\hline & Weight (kg) & 338 & $49.9 \pm 6.3$ & 70 & $50.3 \pm 6.0$ & N.S & 481 & $50.1 \pm 6.5$ & 124 & $50.2 \pm 6.6$ & N.S \\
\hline & BMI $\left(\mathrm{m} / \mathrm{kg}^{2}\right)$ & 339 & $20.2 \pm 2.5$ & 70 & $20.2 \pm 2.1$ & N.S & 482 & $20.3 \pm 2.5$ & 124 & $20.1 \pm 2.6$ & N.S \\
\hline \multicolumn{12}{|c|}{ Distribution of BMI } \\
\hline \multirow{3}{*}{ All } & Over 25.0 & 27 & $4.4 \%$ & 8 & $5.1 \%$ & & 16 & $5.4 \%$ & 41 & $5.2 \%$ & \\
\hline & $18.5-25.0$ & 479 & $77.8 \%$ & 130 & $82.8 \%$ & N.S & 228 & $77.0 \%$ & 610 & $77.1 \%$ & N.S \\
\hline & Under 18.5 & 110 & $17.9 \%$ & 19 & $12.1 \%$ & & 52 & $17.6 \%$ & 140 & $17.7 \%$ & \\
\hline \multicolumn{12}{|c|}{ Self-rated health } \\
\hline \multirow{5}{*}{ All } & Excellent & 236 & $34.4 \%$ & 102 & $58.3 \%$ & \multirow{5}{*}{$0.000^{* * *}$} & 301 & $33.9 \%$ & 157 & $48.6 \%$ & \multirow{5}{*}{$0.000^{* * *}$} \\
\hline & Very good & 328 & $47.8 \%$ & 51 & $29.1 \%$ & & 441 & $49.6 \%$ & 112 & $34.7 \%$ & \\
\hline & Good & 76 & $11.1 \%$ & 13 & $7.4 \%$ & & 87 & $9.8 \%$ & 33 & $10.2 \%$ & \\
\hline & Fair & 40 & $5.8 \%$ & 8 & $4.6 \%$ & & 53 & $6.0 \%$ & 18 & $5.6 \%$ & \\
\hline & Poor & 6 & $0.9 \%$ & 1 & $0.6 \%$ & & 7 & $0.8 \%$ & 3 & $0.9 \%$ & \\
\hline \multirow{5}{*}{ Male } & Excellent & 82 & $28.9 \%$ & 55 & $59.8 \%$ & \multirow{5}{*}{$0.000^{* * * *}$} & 101 & $32.0 \%$ & 79 & $44.4 \%$ & \multirow{5}{*}{ N.S } \\
\hline & Very good & 140 & $49.3 \%$ & 27 & $29.3 \%$ & & 157 & $49.7 \%$ & 67 & $37.6 \%$ & \\
\hline & Good & 36 & $12.7 \%$ & 8 & $8.7 \%$ & & 33 & $10.4 \%$ & 20 & $11.2 \%$ & \\
\hline & Fair & 21 & $7.4 \%$ & 2 & $2.2 \%$ & & 20 & $6.3 \%$ & 10 & $5.6 \%$ & \\
\hline & Poor & 5 & $1.8 \%$ & 0 & $0 \%$ & & 5 & $1.6 \%$ & 2 & $1.1 \%$ & \\
\hline \multirow{5}{*}{ Female } & Excellent & 154 & $38.3 \%$ & 47 & $56.6 \%$ & \multirow{5}{*}{$0.004^{* *}$} & 200 & $34.9 \%$ & 78 & $53.8 \%$ & \multirow{5}{*}{$0.000^{* * *}$} \\
\hline & Very good & 188 & $46.8 \%$ & 24 & $28.9 \%$ & & 284 & $49.6 \%$ & 45 & $31.0 \%$ & \\
\hline & Good & 40 & $10.0 \%$ & 5 & $6.0 \%$ & & 54 & $9.4 \%$ & 13 & $9.0 \%$ & \\
\hline & Fair & 19 & $4.7 \%$ & 6 & $7.2 \%$ & & 33 & $5.8 \%$ & 8 & $5.5 \%$ & \\
\hline & Poor & 1 & $0.2 \%$ & 1 & $1.2 \%$ & & 2 & $0.3 \%$ & 1 & $0.7 \%$ & \\
\hline
\end{tabular}

Note. Significance tested using a Fisher's exact probability test; ${ }^{*} \mathrm{p}<0.05,{ }^{* *} \mathrm{p}<0.01,{ }^{* * *} \mathrm{p}<0.001$ Significance tested using a t-test; $+\mathrm{p}<$ $0.05,++\mathrm{p}<0.01,+++\mathrm{p}<0.001$ 'Presence' (+) means that students dislike more than one foods, 'Absence' $(-)$ means that students disliked no food.

Even in the (+) to $(+)$ group, a significant decreased was observed in the number of disliked food items from childhood $(5.5 \pm 5.4)$ to the present day $(4.2 \pm 4.1)$ ( $\mathrm{P}<0.001$, ANOVA; Figure 1$)$. In male, a significant decreased was observed in the number of disliked food items from childhood $(4.8 \pm 4.9)$ to the present day $(3.6 \pm$ 4.0) ( $\mathrm{P}<0.001$, ANOVA; Figure 1). In female, a significant decreased was observed in the number of disliked food items from childhood $(6.0 \pm 5.7)$ to the present day $(4.5 \pm 4.0)(\mathrm{P}<0.001$, ANOVA; Figure 1$)$. 
Table 2. Relationship between during childhood and at present by gender

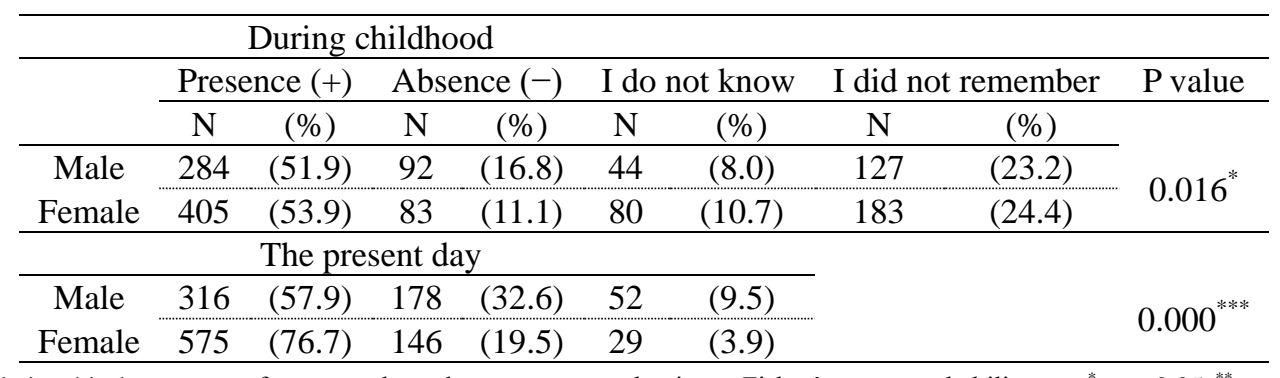

Note. The relationship between preference and gender were assessed using a Fisher's exact probability test; ${ }^{*} \mathrm{p}<0.05,{ }^{* *} \mathrm{p}<0.01,{ }^{* * *} \mathrm{p}<$ 0.001 'Presence' (+) means that students dislike more than one foods, 'Absence' (-) means that students disliked no food.

Table 3. Student's preference of during childhood to high school in relation with gender

\begin{tabular}{|c|c|c|c|c|c|c|c|c|c|}
\hline & \multicolumn{2}{|c|}{$(+) \rightarrow(+)$} & \multicolumn{2}{|c|}{$(+) \rightarrow(-)$} & \multicolumn{2}{|c|}{$(-) \rightarrow(+)$} & \multicolumn{2}{|c|}{$(-) \rightarrow(-)$} & \multirow[b]{2}{*}{$P$ value } \\
\hline & $\mathrm{N}$ & $(\%)$ & $\mathrm{N}$ & $(\%)$ & $\mathrm{N}$ & $(\%)$ & $\mathrm{N}$ & $(\%)$ & \\
\hline Male & 213 & $(59.7)$ & 54 & $(15.1)$ & 23 & $(6.4)$ & 67 & $(18.8)$ & \multirow{2}{*}{$0.000^{\text {**** }}$} \\
\hline Female & 345 & $(72.3)$ & 50 & $(10.5)$ & 31 & $(6.5)$ & 51 & (10.7) & \\
\hline All & 558 & (66.9) & 104 & $(12.5)$ & 54 & $(6.5)$ & 118 & (14.1) & \\
\hline
\end{tabular}

Note. Food preferences of children during childhood to high school in terms of gender were assessed using Fisher's exact probability test; ${ }^{*} P$ $<0.05,{ }^{* *} P<0.01,{ }^{* * *} P<0.001$

$(-)$ means that students disliked no food, $(+)$ means that students dislike more than one foods, $(+)$ to $(+)$, means that the students disliked some foods as childhood and that they disliked some foods as high school days, $(+)$ to $(-)$, means that the students disliked some foods as childhood and that as high school days they disliked no foods, $(-)$ to (+), means that the students disliked no foods as childhood and that as high school days they disliked some foods, $(-)$ to $(-)$, means that the students disliked no foods as childhood and that they disliked no foods as high school days.

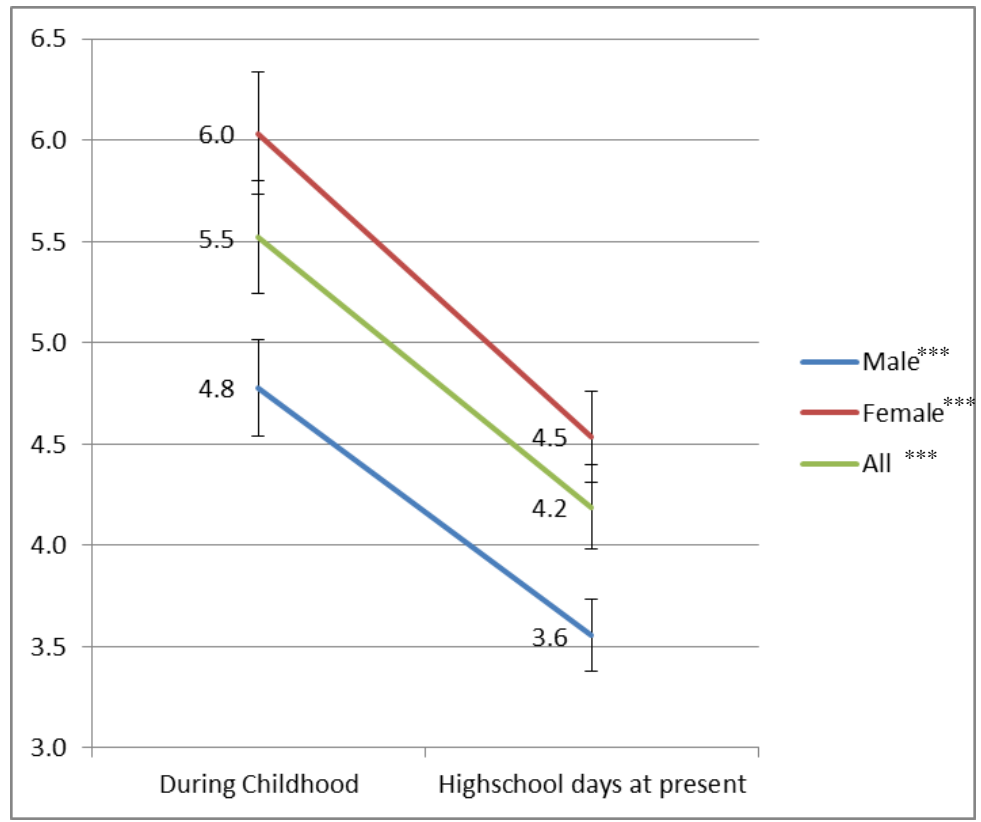

Figure 1. Relationship between the number of their disliked food childhood and high school

Note. The number of their disliked food during childhood to high school in terms of gender were assessed using two way ANOVA; $*$ P < $0.05, * * \mathrm{P}<0.01, * * * \mathrm{P}<0.001$

The foods student disliked, which were chosen themselves from a list of 55 foods. 


\subsection{Relationships between Food Preferences during Childhood to High School Age}

The students' food preferences at present and in childhood exhibited significant relevance for 18 types of vegetables, three types of mushrooms, three types of seafood, and two types of beans $(\mathrm{P}<0.001$, by McNemar test). However, grains, fruits, and meat group were not significantly relevant. Green pepper (41.8\%) was the food preference with the highest improvement rate of $23.8 \%$. Liver and shrimp topped the list of disliked food items reported by the students, but did not exhibit significant changes in preference compared to childhood. In childhood, the top five most disliked foods were green pepper (41.8\%), peas (41.6\%), liver (40.7\%), eggplant (40.0\%), and dried mushroom (32.3\%). The highest rate was liver 38.8\%. Liver exhibited significant changes from childhood to high school age. Now, in high school, the number of disliked food items decreased; green pepper (23.8\%), eggplant (17.9\%), and peas $(17.3 \%)$ had the highest improvement rates $(\mathrm{P}<0.001)$. The most disliked food was vegetables in both childhood and in high school. If children dislike some types of food, when they grow up, they may be improving their preferences (Figure 2).

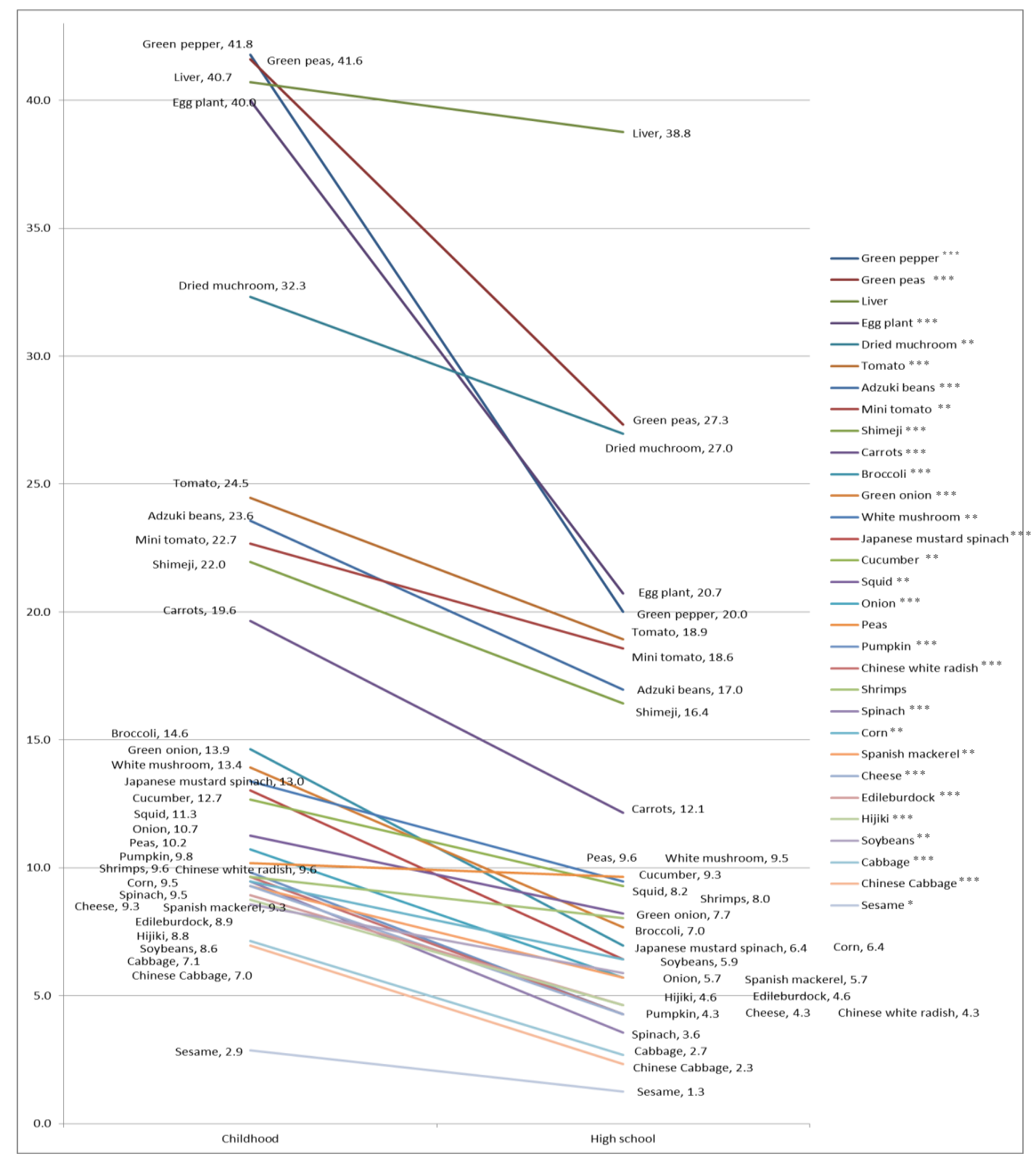

Figure 2. In the detail of each food, relationship between their disliked food childhood and high school.

Note. The percentage of food preferences of children during childhood to high school were assessed using. The foods student disliked, which were chosen themselves from a list of 55 foods. McNemar test; * $\mathrm{P}<0.05$, ** $\mathrm{P}<0.01$, *** $\mathrm{P}<0.001$ 


\subsection{Multiple Logistic Regression Analysis of Factors Affecting Students' Preferences}

No dislike for any food item at present was related to no dislike for any food item during childhood [odds ratio (OR), 12.57; 95\% confidence interval (CI), 8.3-19.1)], talking positively about food (OR, 1.28; 95\% CI, 1.111.49), but inversely related to limited use of smartphone while eating (OR, 0.86; 95\% CI, 0.75-0.98) (Table 4).

Table 4. Means and 95\% confidence intervals of food habits based on current preferences in the high school students after covariate adjustment

\begin{tabular}{llll}
\hline & OR & $(95 \% \mathrm{CI})$ & $P$ value \\
\hline No dislike for any food item during childhood & 12.57 & $(8.29,19.05)$ & 0.000 \\
Talking about food & 1.28 & $(1.11,1.49)$ & 0.013 \\
Limited use of smartphone while eating & 0.86 & $(0.75,0.98)$ & 0.022 \\
\hline
\end{tabular}

OR, Odds ratio; CI, confidence interval Multiple regression analysis by setting a stepwise method

'Talking about food' increases if students talk with their family during meals. Adjusted for gender and age.

\section{Discussion}

According to Tables 1 and 2, food preference influences on health, exhibiting significant differences by gender at high school age. A relationship between height, weight, and food preferences in childhood was observed (P < 0.001). It is important evidence to correct food preference during childhood. In addition, SRH is a measure of the relationship between during childhood and high school age. The utility of SRH assessments has been shown in persons with moderate-to-severe chronic kidney disease (Robinson-Cohen et al., 2014). SRH assessment among adolescents is a good measure of enduring self-concepts of health. It is strongly associated with general well-being and psychosomatic symptoms (Vingilis, Waed, \& Seeley, 2002, Boardman, 2006, Breidablik, Meland, \& Lydersen, 2008, Piko, 2007). SRH was also influenced by gender, family support, lifestyle and psychological factors (Sharif et al., 2016). The result revealed that children's preferences in childhood may be connected with their health when they are at high school age.

In total, $66.9 \%$ of subjects reported $(+)$ to $(+), 12.5 \%$ reported $(+)$ to $(-), 6.5 \%$ reported $(-)$ to $(+)$ and $14.1 \%$ reported (-) to (-) (Table 3). A previous study on children aged 4-6 years in kindergartens revealed similar trends (Osera et al., 2014). The changes in the people's food preference are almost same percentages in childhood and childhood to high school ages.

No dislike for any food item at present was related to no dislike for any food item during childhood (OR, 12.57; 95\% CI, 8.3-19.1), talking positively about food (OR, 1.28; 95\% CI, 1.11-1.49), but inversely related to limited use of smartphone while eating (OR, 0.86; 95\% CI, 0.75-0.98) (Table 4). "Talking about food" and "limited use of smartphone while eating" may be connected with cultural upbringing. Three previous studies of ours suggested that mothers' attitude toward food and eating may have profound effects on children's food preferences (Osera et al., 2012, Osera et al., 2016b). At high school age, it may be important that home and family food environment is similar to that as in childhood. In most cases, the mothers make the dinner (data not shown). So, the mother's role is very important. "Talking about food" rephrase "they eat together." Studies have shown that the meal pattern of skipping breakfast or having "breakfast and lunch together" is related to a less healthy lifestyle and food choices leading to a poorer nutritional intake (Sjoberg et al., 2003). In addition, Stratton described that eating together with the family at meal time was very important for children's development (Stratton, 2003). Taken together, it is suggested that eating while talking to the family positively affects food preference at high school age. In addition, using smartphones is associated with several obesity risk factors (Kenny \& Gortmaker, 2017). Another researcher suggested that depression, anxiety, and daytime dysfunction scores were higher in the high smartphone use group than in the low smartphone use group (Demirci et al, 2015). Therefore, it is suggested that long time using smartphones is related with not only food preferences but also health.

Figures 1 and 2 show that the number of preferences may decrease from childhood to high school age. In the (+) to (+) group, a significant decrease was observed the number of disliked foods from childhood to the present day by gender. Our data described that female have the number of their disliked food over male. The finding corresponds with the previous data about gender influences on food preferences reported by Caine-Bish and Scheule (2009). Gender differences should be considered (Figure 1).

In addition, green pepper and eggplant could be changed (Figure 2). People whose diet comprises more vegetables and fruits have greater longevity and are also protected from heart disease and cancer Bazzano LA (2006). Eating fruits and vegetables has been found to help prevent illness such as cancer and obesity (Ness \& 
Powles, 1997). The more children are exposed to a variety of vegetables, the more likely they are to like those vegetables (Birch \& Marline, 1982). Therefore, it is good for children and adolescents to eat vegetable. According to Figure 1 and Figure 2, as they grew up, their disliked food may be decreased. If children and high school students would like to reduce dislike of food, we found that when the children's "Respect" and "Concern" levels increased, the percentage of children who disliked each of the top 10 disliked foods significantly decreased, showing a similar tendency in the number of foods which children disliked in relation to "Respect" and "Concern" reported by others (Osera et al., 2016a). Importantly, during high school age, children may decrease their preference especially for vegetables.

There are several inherent limitations of the present analysis. A limitation of the current study is that about $30 \%$ of the students answered "I do not know" or "I do not remember." It was also a limitation that it was a retrospective study due to recall bias. In addition, we only reported associations. We could not clearly demonstrate a cause and effect relationship. This study suggested a relationship between children's food preference and subsequent high school SRH and height and weight in males, but we do not know the strength of the health effects. In the next study, we will try to do the investigation or cohort study.

In conclusion, less dislike for certain foods in high school students was related to eating with somebody at present day as well as a lower number of dislike food items in childhood. Decreasing the dislike for foods at present as well as no dislike for any food item in childhood may be critical to developing good food habits in the future of high school students.

\section{Acknowledgments}

We thank all the students and teachers in Japan for their contributions to this study. We are also grateful to the teachers for their assistance.

\section{Author contributions}

Tomoko Osera, Setsuko Tsutie, and Nobutaka Kurihara developed the standardized protocol and structured questionnaire. Mitsuyo Awai, Misako Kobayashi conducted the focus group research in the high school. Tomoko Osera drafted the manuscript. All authors critically revised the article for important intellectual content and approved the final manuscript.

\section{Conflict of interest}

The authors declare that they have no conflict of interest.

\section{References}

Bazzano, L. A. (2006). The high cost of not consuming fruit and vegetables. Journal of American Diet Association, 106, 1364-1368. http://dx.doi.org/10.1016/j.jada.2006.06.021

Birch, L. L., \& Marlin, D. W. (1982). I don't like it; I never tried it: Effects of exposure on two-year-old children's food preferences. Appetite, 3, 353-360. https://doi.org/10.1016/S0195-6663(82)80053-6

Boaedman, J. D. (2006). Self-rated health among US adolescents. Journal of Adolescent Health, 38, 401-408. http://dx.doi.org/10.1016/j.jadohealth.2005.01.006

Breidablik, H. J., Meland, E., \& Lydersen, S. (2008). Self-rated health in adolescence: a multifactorial composite. Scandinavian Journal of Public Health, 36, 12-20. http://dx.doi.org/10.1177/1403494807085306

Caine-Bish, N. L. \& Scheule, B. (2009). Gender differences in food preferences of school-aged children and adolescents. Journal of School Health, 79, 532-540. http://dx.doi.org/10.1111/j.1746-1561.2009.00445.x

Cashidan, E. (1994). A sensitive period for learning about food. Human Nature, 5, $279-291$. http://dx.doi.org/10.1007/BF02692155

Demirci, K., Akgonul, M., \& Akpinar, A. (2015). Relationship of smartphone use severity with sleep quality, depression, and anxiety in university students. Journal of Behavioral Addictions, 4, 85-92. http://dx.doi.org/10.1556/2006.4.2015.010

Deshmukh-Taskar, P., Nicklas, T. A., Yang, S., Berenson, G. S. (2007). Does Food Group Consumption Vary by Differences in Socioeconomic, Demographic, and Lifestyle Factors in Young Adults? The Bogalusa Heart Study. Journal American Diet Association, 107, 223-234. http://dx.doi.org/10.1016/j.jada.2006.11.004

Ilingworht, R. S., \& Lister, J. (1964). The critical or sensitive period, with special reference to certain feeding problems in infants and children. The journal of Pediatrics, 65, 839-848.

http://dx.doi.org/10.1016/S0022-3476(64)80006-8 
Japan Sports Council. The report of food habits of elementary school children and junior high school students. (2010). http://www.jpnsport.go.jp/anzen/anzen/_school/tyosakekka/tabid/1490/Default.aspx (accessed 5 April 2017)

Joffer, J., Jerden, L., Ohman, A., \& Flacking, R. (2016). Exploring self-rated health among adolescents: a think-aloud study. BMC Public Health, 16, 156. http://dx.doi.org/10.1186/s12889-016-2837-z

Kenney, E.L., \& Gortmaker, S. L. (2016). United States Adolescents' Television, Computer, Videogame, Smartphone, and Tablet Use: Associations with Sugary Drinks, Sleep, Physical Activity, and Obesity. The Journal of Pediatrics, 182, 144-149. http://dx.doi.org/10.1016/j.jpeds.2016.11.015

Mechanic, D., \& Hansell, S. (1987). Adolescent competence, psychological well-being, and self-assessed physical health. Journal of Health and Social Behavior, 28, 364-74.

Ness, A. R., \& Powles, J. W. (1997). Fruit and vegetables, and cardiovascular disease: A review. International Journal of Epidemiology, 26, 1-13. https://doi.org/10.1093/ije/26.1.1

Nicklas, T. A., Baranowski, T., Baranowski, J. C., Cullen, K., Rittenberry, L., \& Olvera, N. (2001). Family and child- care provider influences of preschool children's fruit, juice, and vegetables consumption. Nutrition Reviews, 59, 224-235. http://dx.doi.org/10.1111/j.1753-4887.2001.tb07014.x

Osera, T., Tsutie, S., Kobayashi, M., \& Kurihara, N. (2012). Relationship of mothers' food preferences and attitudes with children's preferences. Food and Nutrition Sciences, 3, 1461-1446. http://dx.doi.org/10.4236/fns.2012.310190

Osera, T., Tsutie, S., Kobayashi, M., \& Kurihara, N. (2014). A retrospective study on the relationship of changes in likes/dislikes with food habits in 4- and 6-year-old children. European Journal of Nutrition \& Food Safety, 4, 604-613. http://dx.doi.org/10.9734/EJNFS/2014/10604

Osera, T., Tsutie, S., Kobayashi, M., \& Kurihara, N. (2016a). Associations between children's food preferences and food haibts towards healthy eating in Japanese children. Journal of Children \& Adolescent Behavior, 4, 1000292. http://dx.doi.org/10.4172/2375-4494.1000292

Osera, T., Tsutie, S., Kobayashi, M., Segawa, Y., Kajiwara, C., Hashimoto, H., et al. (2016b). The effect of mothers' and fathers' food preferences on children's preferences with their attitude. European Journal of Nutrition \& Food Safety, 6, 93-100. http://dx.doi.org/10.9734/EJNFS/2016/24085

Piko, B. F. (2007). Self-perceived health among adolescents: the role of gender and psychosocial factors. European Journal of Pediatrics, 166, 701-708. http://dx.doi.org/10.1007/s00431-006-0311-0

Robinson-Cohen, C., Hall, Y. N., Reindl, M., \& Vega, W. A. (2014). Validity of self-rated health aong lation(a)s. American Journal of Epidemiology, 155, 755-759. https://doi.org/10.1093/aje/155.8.755

Scaglioni, S., Salvioni, M., \& Galimberti, C. (2008). Influence of parental attitudes in the development of children eating behavior.British Journal of Nutrition, 99(Supple 1), S22-25. http://dx.doi.org/10.1017/S0007114508892471

Sharif, M. Z., Rizzo, S., Marino, E., Belin, T. R., Glik, D. C., Kuo, A. A., et al. (2016). The association between self-rated eating habits and dietary behavior in two neighborhoods: Findings from Proyecto Mercado FRESCO. Preventive Medicine Reports, 3, 270-275.

Sharma, B., Nam, E. W., Kim, D., Yoon, Y. M., Kim, Y., \& Kim, H. Y. (2016). Role of gender, family, lifestyle and psychological factors in self-rated health among urban adolescents in Peru: a school-based cross-sectional survey. BMJ open, e010149. http://dx.doi.org/10.1136/bmjopen-2015-010149

Sjoberg, A., Hallberg, L., Hoglund, D., \& Hulthen, L. (2003). Meal pattern, food choice, nutrition intake and lifestyle factors in the Hoteborg adolescence study. European Journal of Clinical Nutrition, 57, 1569-1578. http://dx.doi.org/10.1038/sj.ejen.1601726

St-Onge, M. P., Keller, K. L., Heymsfield, S. B. (2003). Changes in childhood food consumption patterns: a cause for concern in light of increasing body weights. American Journal of Clinical Nutrition, 78, 1068-1073.

Stratton, P. (2003). Contemporary families as contents for development. In: Valsiner J, Connolly, KJ (ed.) Handbook of developmental psychology. London: SAGE pp: 333-357.

Viner, R. M., Ozer, E. M., Denny, S., et al. (2012). Adolescence and the social determinants of health. Lancet, 379, 1641-52. http://dx.doi.org/10.1016/S0140-6736(12)60149-4 
Vingilis, E., Wade, T., \& Seeley, J. (2002). Predictors of adolescent self-rated health. Analysis of the National Population Health Survey. Canadian Journal of Public Health, 93, 193-197.

Vingilis, E., Wade, T., \& Seeley, J. (2007). Predictors of adolescent health care utilization. Journal of Adolescence, 30, 773-800. https://doi.org/10.1016/j.adolescence.2006.10.001

Warde, J \& Cooke, L. (2008). “Genetic and environmental determinants of children's food preference. Journal of Nutrition, 99, S15-21.

Warnoff, C., Lekander, M., Hemmingsson, T., Sorjonen, K., Melin, B., \& Andreasson, A. (2016). Is poor self-rated health associated with low-grade inflammation in 43110 late adolescent men of the general $\begin{array}{llllll}\text { population? A cross-sectional study. BMJ Open, } & \text { e009440. }\end{array}$ http://dx.doi.org/10.1136/bmjopen-2015-009440

Wu, S., Wang, R., Zhao, Y., Ma, X., Wu, M., Yan, X., et al. (2013). The relationship between self-rated health and objective health status: a population-based study. BMC Public Health, 13, 320.

http://dx.doi.org/10.1186/1471-2458-13-320

\section{Copyrights}

Copyright for this article is retained by the author(s), with first publication rights granted to the journal.

This is an open-access article distributed under the terms and conditions of the Creative Commons Attribution license (http://creativecommons.org/licenses/by/3.0/). 